\title{
Diffuse membranous glomerulonephritis in children
}

\author{
W. C. CHAN AND Y. C. TSAO \\ From the Department of Pathology and the Paediatric Unit, University of Hong Kong
}

SYNOPSIS Nine cases of diffuse membranous glomerulonephritis detected among 90 renal biopsies from children with persistent proteinuria and one necropsy case of a young child who died of chronic membranous glomerulonephritis with uraemia were studied by a variety of techniques. Clinical presentation varies within this single morphological entity and the response to steroid therapy is not yet predictable on either clinical or morphological criteria. Correlation is demonstrated between therapeutic responses and the degree of selectivity of the proteinuria which was determined by studying the relative protein clearances with an immunochemical technique.

In several published series renal biopsies from patients with the nephrotic syndrome, i.e., with hypoproteinaemia, proteinuria, oedema, and hypercholesterolaemia, were studied and grouped into various morphological entities according to the histological features of the kidney (Blainey, Brewer, Hardwicke, and Soothill, 1960; Mackay and Taft, 1961; McGovern, 1964). Among the morphological groups, membranous glomerulonephritis is well recognized. In the study of renal biopsies from 90 Chinese children with persistent proteinuria of whom a minority did not have the nephrotic syndrome, nine patients were found to have membranous glomerulonephritis. Renal tissue was obtained a second time in four of them. A tenth patient came to necropsy. These 10 children are the subject of the present investigation.

When it is well established, membranous glomerulonephritis is readily distinguishable from other renal changes that are found in persistent proteinuria, because a diffuse thickening of the basement membrane of the glomerular capillaries can be seen by light microscopy, especially if periodic-acid-Schiff staining is used.

Conventional histological techniques were supplemented by fluorescence antibody technique in the study of the renal biopsy material. Urinary protein clearance estimations based on an immunochemical method were carried out on six of the cases. The pathological findings are compared with the clinical features.

Received for publication 4 May 1966.
METHODS

RENAL BIOPSY Renal biopsies were performed by the method of White (1963), using his modification of the Silverman biopsy needle (1962). Usually, two pieces of renal tissue were obtained. Each was subjected to a separate procedure.

Fresh, unfixed renal tissue was cut on an International cryostat at $6 \mu$ and the sections were stained according to Coons' technique (Coons and Kaplan, 1950) for human gamma globulin, using fluorescein-tagged anti-humangamma-globulin goat serum (Sylvana Co., Los Angeles, California, U.S.A.). The sections were examined under a Leitz Ortholux microscope with a Phillips 150W mercury-vapour lamp. An apple-green fluorescence indicated the presence of gamma globulin. Control sections were pre-treated with anti-human-gamma-globulin goat serum unconjugated with fluorescein before the above staining procedure was carried out; this extinguished the specific fluorescence.

The second piece of tissue was fixed in $10 \%$ neutral formalin and embedded in Esterwax. Sections were cut at $2 \mu$ and were stained by Lilli-Mayer haematoxylin and eosin, periodic-acid-Schiff, and Masson's trichrome techniques.

DIFFERENTIAL PROTEIN CLEARANCE STUDIES A 24-hour collection of clean voided urine was received into a container together with a drop of $10 \%$ sodium azide as preservative. The total volume was measured and an aliquot taken for protein clearance study. Sometimes the protein in question is present in such a small amount that concentration of the urine is necessary before the test. Two blood samples were taken during the 24-hour period: a heparinized specimen for use in the immuno-chemical 
analysis of protein and a clotted specimen for chemical determination of serum protein.

Immuno-chemical study of the plasma proteins passed in the urine was carried out by the double gel-diffusion technique described by Gell (1957). The percentage clearances of five proteins with reference to the siderophilin clearance were calculated using the method described by Joachim, Cameron, Schwartz, and Becker (1964). The proteins siderophilin (transferrin), orosomucoid, albumin, 7S gamma globulin, alpha 2 macroglobulin and beta-lipoprotein were identified semiquantitatively by means of the specific antisera (Hyland). The urine:plasma concentration (U/P) ratio of each of the six proteins was estimated by matching the precipitate lines on a specially cut agar plate. The wells in the plate contained the urinary and plasma proteins of the patient in different concentrations. These antigen wells were encircled by smaller wells containing the specific antiserum in serial dilution. The $\mathbf{U} / \mathbf{P}$ of the protein in question divided by the $U / P$ of siderophilin multiplied by 100 gives the percentage clearance of the protein with reference to siderophilin clearance (Joachim et al., 1964). These percentages were then plotted against the respective molecular weights in a log-log graph and the angle between the line so obtained and the abscissa was measured. In this technique the resultant angle theta $(\theta)$ is taken as a measure of the selectivity of the proteinuria.

\section{CLINICAL PRESENTATION}

The cases can be divided into three groups according to the clinical presentation (Table I).

1 SYMPTOMLESS PROTEINURIA (ONE CASE) A 7-year-old boy was referred to us because of the incidental finding of proteinuria during a routine examination for adoption purposes. The proteinuria was persistent and not related to either posture or exercise. With steroid therapy proteinuria disappeared and has not recurred over 10 months.

2 NEPHROTIC SYNDROME (EIGHT CASES) This group can be subdivided into: (a) Cases responding well to steroid therapy In four cases, proteinuria disappeared under steroid treatment; symptoms were generally mild or of short duration and in each patient the period of remission was long and although there were relapses, they were widely spaced.

(b) Cases responding poorly to steroid therapy In the other four cases, frequent relapses were encountered and symptoms generally required longer treatment for control. The improvement was mainly clinical, as shown by the disappearance of the oedema, and by increase in general well being of the patients. In fact all four patients enjoyed ordinary activities while in remission. The proteinuria diminished but did not disappear, usually settling to a minimal level.

3 CHRONiC AZOTAEMIC RENAL FAILURE (ONE CASE) A 5-year-old boy, who had no known previous renal disease, was admitted in uraemia and died after transient improvement following peritoneal dialysis and conservative treatment. Investigation showed albuminuria ++ , blood urea $248 \mathrm{mg} . / 100 \mathrm{ml}$., blood pressure $160 / 100 \mathrm{~mm}$. $\mathrm{Hg}$; plasma $\mathrm{CO}_{2}$-combining power $6 \mathrm{mEq}$./litre; serum sodium $144 \mathrm{mEq}$./litre, potassium $3.8 \mathrm{mEq}$./litre, chloride $121 \mathrm{mEq}$./litre, calcium $8 \mathrm{mg} . / 100$ ml., phosphorus $6.6 \mathrm{mg} . / 100 \mathrm{ml}$.; albumin $1.7 \mathrm{~g} . / 100 \mathrm{ml}$., and globulin $2.8 \mathrm{~g} . / 100 \mathrm{ml}$. At necropsy, there was diffuse glomerular basement membrane thickening, and some fibrosis (Fig. 1) of the kidney. There were also deposits of cholesterol in the interstitial tissue.

\section{TREATMENT}

All patients were treated with prednisone. The starting dose was $1 \mathrm{mg}$./lb./day in divided doses. This was maintained until there was satisfactory clinical remission as shown by subsidence of oedema and reduction of proteinuria. The dose was then gradually reduced over a period of about 10 days until it was halved. After the blood cholesterol, serum proteins and proteinuria had been stabilized at a satisfactory level for at least a fortnight, the dose was further reduced to a minimum maintenance level. The latter was determined by trial and error.

TABLE I

GROUPING OF CASES AND RESULTS OF INVESTIGATIONS AND STEROID TREATMENT

\begin{tabular}{|c|c|c|c|c|c|c|c|c|c|}
\hline \multirow{3}{*}{$\begin{array}{l}\text { Clinical } \\
\text { Group }\end{array}$} & \multirow[t]{3}{*}{ Case } & \multirow[t]{3}{*}{ Age } & \multirow[t]{3}{*}{ Sex } & \multirow{3}{*}{$\begin{array}{l}\text { Response to } \\
\text { Treatment }\end{array}$} & \multicolumn{2}{|c|}{ Fluorescent Staining } & \multicolumn{2}{|c|}{ Membrane Thickening } & \multirow{3}{*}{$\begin{array}{l}\text { Selectivity } \\
\text { Angle } \theta\end{array}$} \\
\hline & & & & & \multicolumn{2}{|c|}{ Biopsy } & \multicolumn{2}{|c|}{ Biopsy } & \\
\hline & & & & & First & Second & First & Second & \\
\hline 1 & C.S.C. & 7 & $\mathbf{M}$ & Good & + & 0 & + & + & - \\
\hline $2 a$ & $\begin{array}{l}\text { C.P.C. } \\
\text { W.C.W. } \\
\text { C.Y.F. } \\
\text { F.W.T. }\end{array}$ & $\begin{array}{r}6 \\
10 \\
8 \\
4\end{array}$ & $\begin{array}{l}\mathbf{M} \\
\mathbf{M} \\
\mathbf{M} \\
\mathbf{M}\end{array}$ & $\begin{array}{l}\text { Good } \\
\text { Good } \\
\text { Good } \\
\text { Good }\end{array}$ & $\begin{array}{l}+ \\
+ \\
+\end{array}$ & $\begin{array}{l}- \\
- \\
+ \\
\mathbf{D}\end{array}$ & $\begin{array}{l}+ \\
+ \\
+ \\
+\end{array}$ & $\begin{array}{l}- \\
\overline{-} \\
+ \\
+\end{array}$ & $\begin{array}{l}70^{\circ} \\
- \\
68^{\circ}\end{array}$ \\
\hline $2 b$ & $\begin{array}{l}\text { K.C.Y. } \\
\text { Y.K.K. } \\
\text { L.Y.H. } \\
\text { Y.C.H. }\end{array}$ & $\begin{array}{r}10 \\
6 \\
9 \\
9\end{array}$ & $\begin{array}{l}\mathbf{F} \\
\mathbf{M} \\
\mathbf{M} \\
\mathbf{F}\end{array}$ & $\begin{array}{l}\text { Poor } \\
\text { Poor } \\
\text { Poor } \\
\text { Poor }\end{array}$ & $\begin{array}{l}+ \\
+ \\
+ \\
-\end{array}$ & $\begin{array}{l}- \\
- \\
\overline{+}\end{array}$ & $\begin{array}{l}+ \\
+ \\
+ \\
+\end{array}$ & $\begin{array}{l}- \\
- \\
\overline{+}\end{array}$ & $\begin{array}{l}60^{\circ} \\
62^{\circ} \\
62^{\circ} \\
57^{\circ}\end{array}$ \\
\hline 3 & L.C.K. & 5 & $\mathbf{M}$ & - & - & - & + & - & - \\
\hline
\end{tabular}




\section{RESULTS OF INVESTIGATIONS}

HISTOLOGY All 10 cases showed diffuse thickening of the basement membrane. Certain additional histological findings deserve comment.

Glomeruli with basement membrane thickening occurred side by side with glomeruli showing minimal changes in the group 1 case and also in patient W.C.W. in group $2 a$ (Figs. 2 and 3 ).

In most of the group 2 patients the diffuse thickening of the basement membrane was seen in all the glomeruli of the biopsy specimens without any proliferative changes. In some, the lumen of the capillary was prominent (Fig. 4); in others, it was narrowed (Fig. 5); some secondary tubular degenerative changes were present.

Y.C.H. in group $2 b$ had mixed membranous and proliferative changes in the same glomerulus (Fig. 6). The glomeruli were hypercellular as well as showing diffuse basement membrane thickening. The tubules

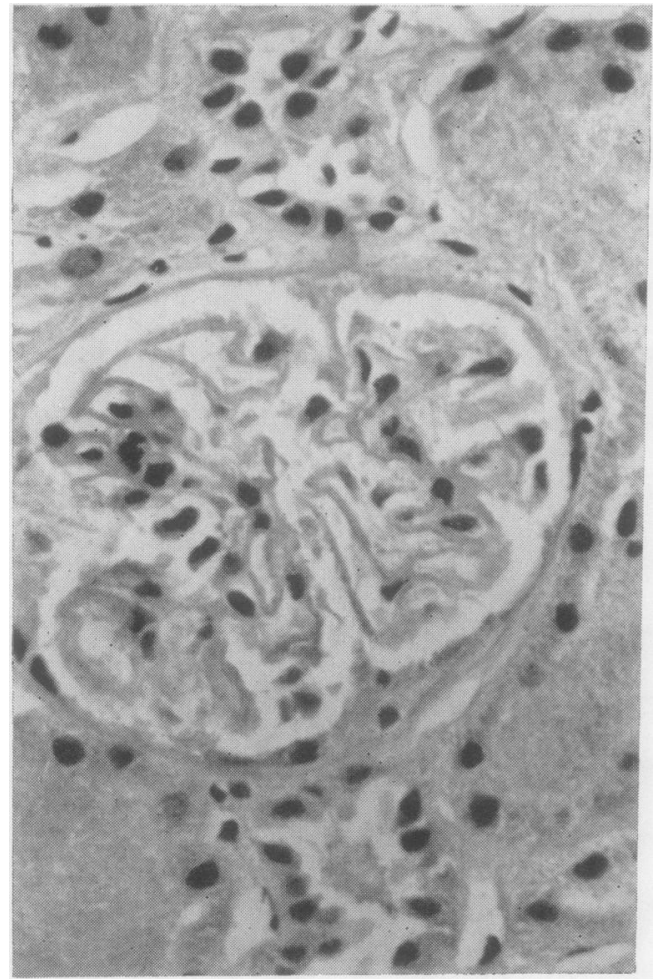

FIG. 2 and the interstitium showed no remarkable features.

In the group 3 patient, many glomeruli were sclerosed, and there was an increase in the interstitial connective tissue and an atrophy of many renal tubules (Fig. 1).

IMMUNO-FLUORESCENCE TECHNIQUE Deposits of gamma globulin in the region of the thickened glomerular basement membrane (Fig. 7) were demonstrated in all the nine cases studied by the fluorescent antibody technique. In the patient C.S.C. with symptomless proteinuria, gamma globulin was not demonstrable in the unaffected glomeruli of the first biopsy nor in any glomeruli in the second renal biopsy performed eight months after the proteinuria had disappeared. In F.W.T. in group $2 a$ the fluorescent staining was markedly reduced three weeks after the clinical remission had been achieved, although a trace of protein persisted in the urine.

Differential protein clearance studies were done in

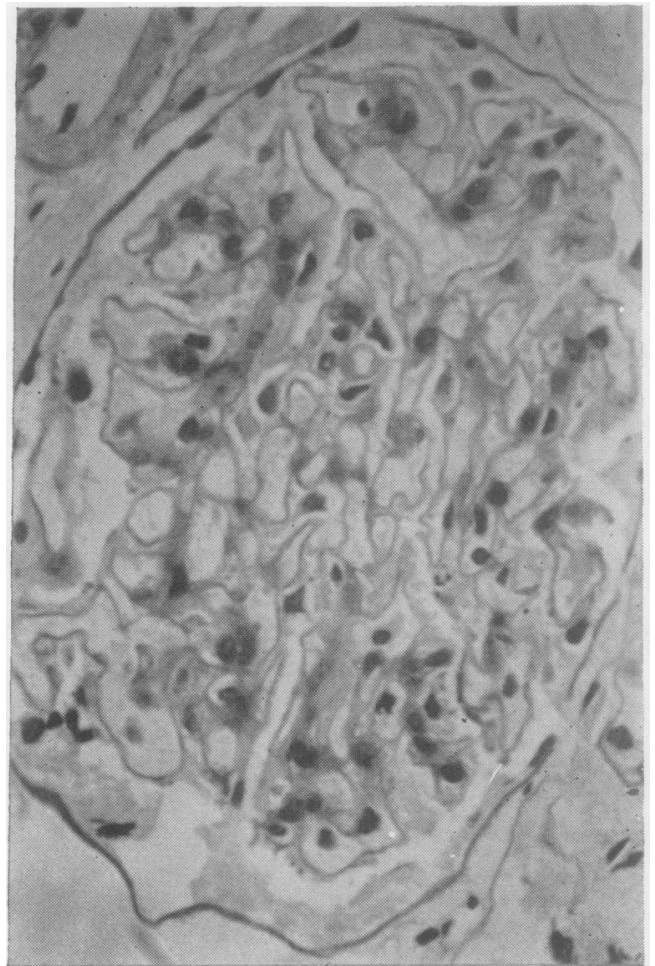

FIG. 3

FIG. 2. W.C.W. Diffuse basement membrane thickening in a glomerulus in which positive fluorescence for gamma globulin was demonstrated. Haematoxylin and eosin $\times 510$.

FIG. 3. Same case as in Figure 2. Minimal change in glomerulus in which globulin was not demonstrated. Haematoxylin and eosin $\times 510$. 


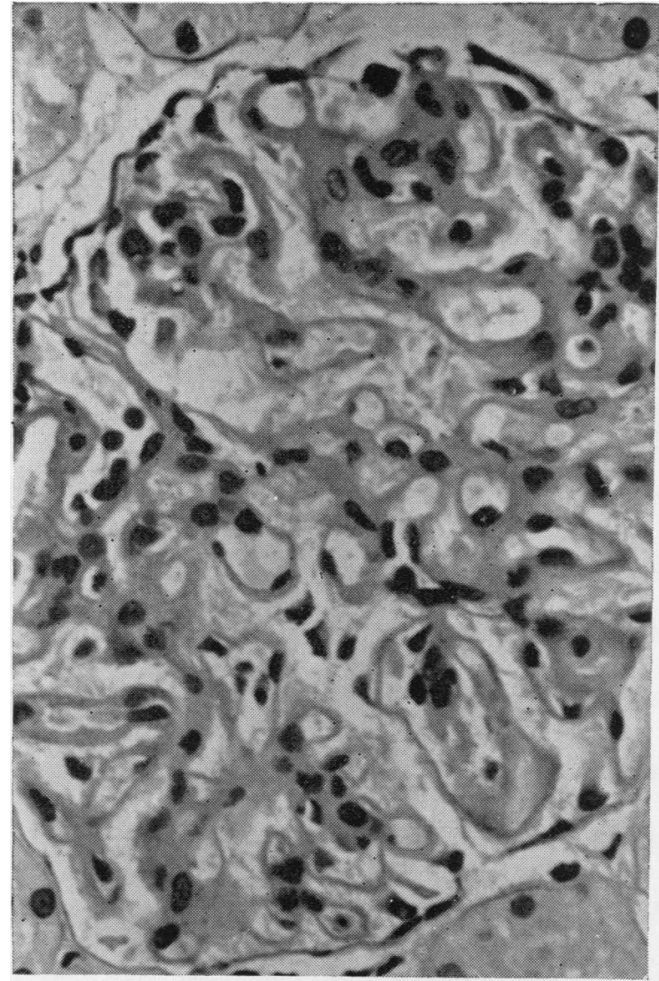

FIG. 4

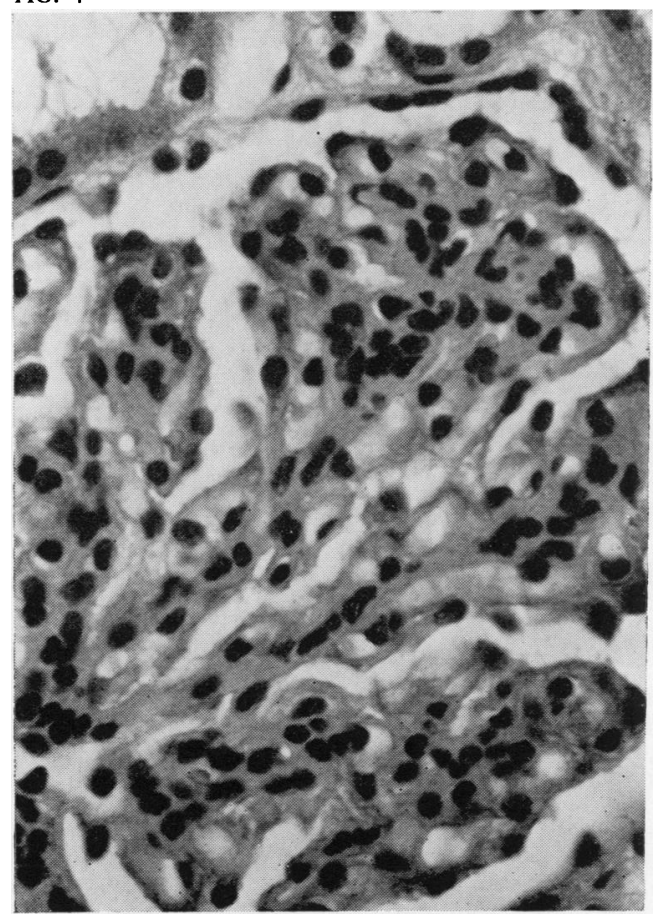

FIG. 6

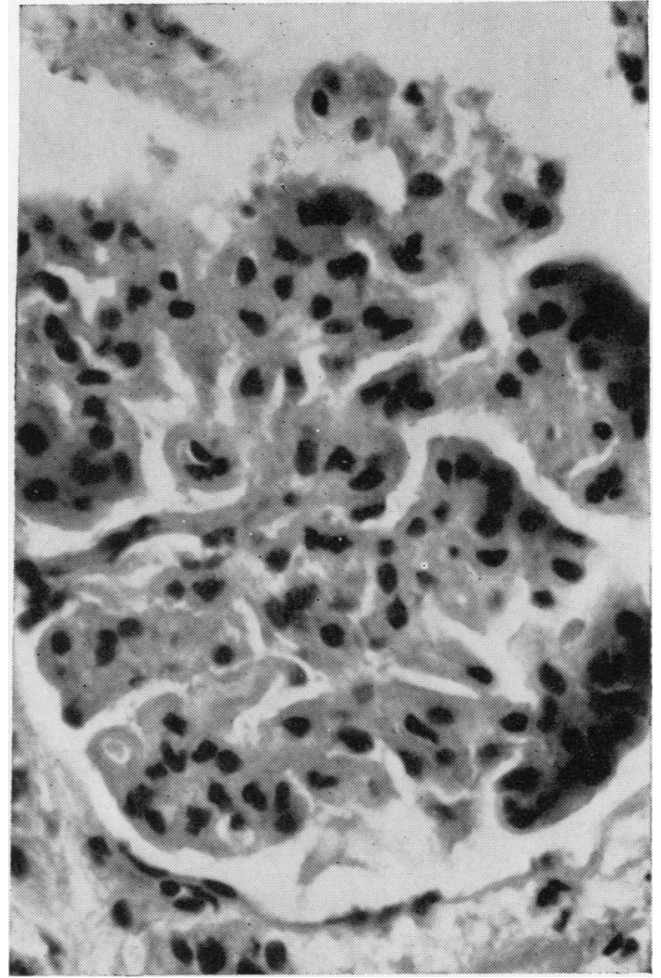

FIG. 5

FIG. 4. C.Y.F. Diffuse basement-membrane thickening in glomerulus in which capillary lumen is preserved. Haematoxylin and eosin $\times 510$.

FIG. 5. K.C.Y. Marked basement-membrane thickening; capillary lumen narrowed. Haematoxylin and eosin $\times 510$.

FIG. 6. Y.C.H. Basement-membrane thickening and proliferative changes are both present in the glomerulus. Haematoxylin and eosin $\times 510$. 


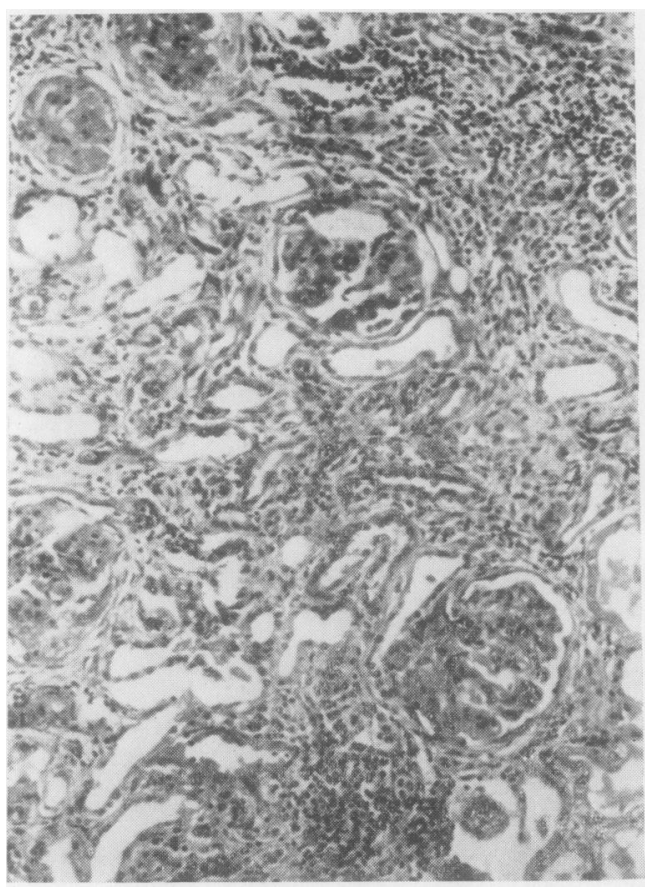

FIG. 1. L.C.K. Post-mortem section; basement membrane thickening with sclerosis of glomeruli. Haematoxylin and eosin $\times 126$.

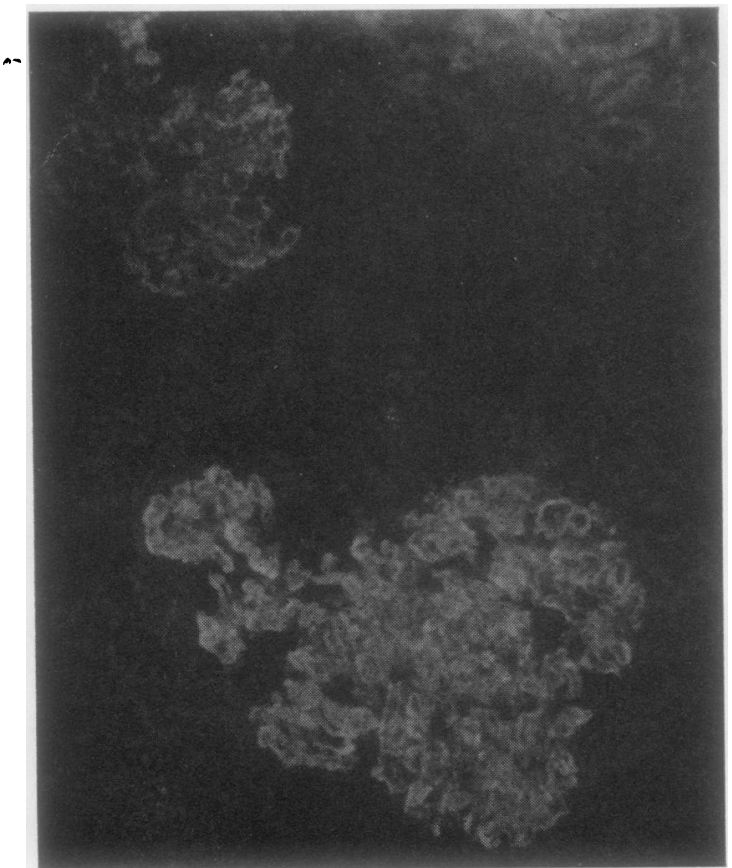

FIG. 7. C.Y.F. Fluorescent staining of glomeruli showing presence of gamma globulin in the position of basement membrane $\times 300$. six of the patients. The results are expressed as the angle $\theta$ in Table I. A low selectivity is indicated by a low value for the angle.

\section{DISCUSSION}

Membranous glomerulonephritis is a distinctive structural entity, although it is probably not a specific disease. Allen (1962) maintains that the membranous thickening is a basic pathogenic lesion in the production of the nephrotic syndrome; however, most other workers found that not all nephrotic patients have membranous thickening in the glomeruli (Blainey et al., 1960; Mackay and Taft, 1961; McGovern, 1964). We can confirm this latter finding. Occasionally, the membranous thickening is not associated with the nephrotic syndrome, as shown in the child in group 1 . He presented only with persistent proteinuria. At the other extreme, the patient in group 3 passed silently to the final stage of renal failure without any previous history of the nephrotic syndrome. From these findings, it appears, the condition membranous glomerulonephritis may present in a variety of ways depending on its stage. Early on this lesion may cause only a proteinuria; as it advances, hypoproteinuria, oedema, and hypercholesterolaemia may make their appearance, and finally renal function may fail.

Apart from the diffuse membrane thickening, renal tissuefromall patients who were biopsied and studied by the immunofluorescent technique showed the presence of gamma globulin in the glomeruli. The origin of gamma globulin localized in the basement membrane has been discussed by Mellors, Ortega, and Holman (1957). Possibly gamma globulin collects there because of entirely mechanical factors such as trapping of the large protein molecules or soluble antigen antibody complexes while they leak through the glomerular filter. It is difficult, however, to reconcile this hypothesis with the fact that positive fluorescent staining in the glomeruli is restricted to cases with diffuse basement membrane thickening and to a few other conditions such as disseminated lupus erythematosus, Henoch-Schönlein syndrome, and to some cases of acute glomerulonephritis. Gamma globulin is not found in the glomeruli in cases of nephrotic syndrome even at times when this protein is being passed in the urine (unpublished observations). It is not even possible to correlate the presence of gamma globulin solely with the selectivity of the proteinuria, because gamma globulin is not identifiable in kidney tissue from cases with glomerulosclerosis or from some cases of acute glomerulonephritis in which the degree of selectivity of the proteinuria is low (Blainey et al., 1960; Joachim et al., 1964). In the patients tested, in 
group $2 a$ the selectivity was good, yet positive fluorescence was demonstrated in all the biopsies. Our findings suggest that the deposition of gamma globulin in the basement membrane results from proteinuria occurring in the presence of a thick basement membrane and possibly from other factors as well.

The group 1 patient with symptomless proteinuria and patients in group $2 a$ with minimal clinical manifestation responded well to steroid therapy, but the long-term prognosis is still uncertain and we do not know if the kidney lesions we found were irreversible. The membranous change persisted in a repeat biopsy 20 months after the first in the child C.Y.F. in group $2 a$. This patient did not attend the follow-up clinic regularly and received steroid only periodically during relapses. The other repeat biopsies all showed persistence of the membranous change, although two showed disappearance or diminution of the gamma globulin attached to the glomeruli.

Hitherto, diffuse membranous glomerulonephritis has been considered as a condition that responds poorly to treatment and carries a bad prognosis. That is the rule in adults, and it applies equally to some children as in case L.C.K. in group 3. Yet all the other patients are alive, some several years after the diagnosis was made, and some responding well to steroid therapy. Others, like their adult counterpart, are difficult to control clinically and the response to similar therapy disappointing. This variation in the response to treatment within the same morphological group is also observed by Cameron and Becker (1966, cited by Hardwicke, 1965). Hardwicke, however, thinks that all cases of membranous glomerulonephritis respond poorly to treatment and he attributes the divergent clinical courses encountered to the different criteria of diagnosis. We have found no difference in the morphology of glomeruli in groups $2 a$ and $2 b$ other than an occasional sclerosed glomerulus in group $2 b$ which betrays the chronicity of the condition. The patient L.C.K. who came to necropsy exhibited all the features of a chronic membranous glomerulonephritis.

Differential protein clearance studies using the double gel diffusion technique showed a higher selectivity $(\theta=72$ and 68$)$ in cases in which the response to steroid therapy was good, and a lower selectivity $(\theta=57$ and 60$)$ in those cases with poor response. These indices are in agreement with Cameron and White's findings in children (1965) and are considerably higher than those of Blainey $e t$ al. (1960) in adults. The selectivity of the proteinuria in groups 1 and $2 a$ was of the same order as that found in children with nephrotic syndrome with minimal renal changes (unpublished observation). The protein clearance technique appears to be useful in predicting the response to therapy, an observation in agreement with Cameron and Becker (1966) but not with Hardwicke (1965).

The repeat biopsies in this series all show persistence of the membranous change. It is reasonable to suppose that it is unlikely that there will be morphological improvement in the patients who respond poorly to treatment. The three patients who respond well to treatment, however, also show persistence of the change. One of them, C.Y.F., has not had adequate treatment, and the other two show disappearance or diminution of gamma globulin in the glomeruli when the proteinuria disappears. This makes one hopeful that prolonged and adequate treatment may yet restore the glomeruli to normal, if sclerosis has not set in. The follow-up of this series is short; only time will tell whether this reversion will occur.

We are grateful to Professors J. B. Gibson and C. E. Field for encouragement and interest in this investigation and for constructive criticism. This work is generously supported by a grant from the $\mathrm{Li}$ Shu Fan Medical Foundation, Hong Kong. Messrs. K. H. Lau and Y. S. Wong gave valuable technical assistance.

\section{REFERENCES}

Allen, A. C. (1962). The Kidney, 2nd ed., p. 248. Grune and Stratton, New York.

Blainey, J. D., Brewer, D. B., Hardwicke, J., and Soothill, J. F. (1960) Quart. J. Med., 29, 235.

Cameron, J. S., and Becker, E. L. (1966). J. clin. Invest., in the press. Cited by Hardwicke (1965).

- -, and White, R. H. R. (1965). Lancet, 1, 463.

Conos, A. H., and Kaplan, M. H. (1950). J. exp. Med., 91, 1

Geii, P. G. H. (1957). J. clin. Path., 10, 67.

Hardwicke, J. (1965). Ibid., 18, 559.

Joachim, G. R., Cameron, J. S., Schwartz, M., and Becker, E. L. (1964). J. clin. Invest., 43, 2332.

McGovern, V. J. (1964). Aust. Ann. Med., 13, 306.

Mackay, I. R., and Taft, L. I. (1961). Ibid., 10, 178.

Mellors, R. C., Ortega, L., and Holman, H. R. (1957). J. exp. Med., 106, 191.

White, R. H. R. (1962). Lancet, 1, 673.

(1963). Arch. Dis. Childh., 38, 260. 